\title{
Can serum homocysteine predict hypertensive disorders of pregnancy?: an evidence from a case control study in a North Indian tertiary health care institution
}

\author{
Kushla Pathania $^{1}$, S. K. Verma ${ }^{1}$, Shaina Chamotra ${ }^{1 *}$, Ankit Chaudhary ${ }^{2}$
}

\author{
${ }^{1}$ Department of Obstetrics and Gynecology, KNH, IGMC Shimla, Himachal Pradesh, India \\ ${ }^{2}$ Department of Community Medicine, IGMC Shimla, Himachal Pradesh, India
}

Received: 19 May 2019

Accepted: 01 July 2019

\author{
*Correspondence: \\ Dr. Shaina Chamotra, \\ E-mail: chamotra47@gmail.com
}

Copyright: ( $)$ the author(s), publisher and licensee Medip Academy. This is an open-access article distributed under the terms of the Creative Commons Attribution Non-Commercial License, which permits unrestricted non-commercial use, distribution, and reproduction in any medium, provided the original work is properly cited.

\begin{abstract}
Background: Hypertensive disorders of pregnancy are a major cause of both maternal and foetal morbidity and mortality. Although pregnancy induced hypertension (PIH) is still regarded as a disease of theories and unknown etiology, elevated homocysteine level has been hypothesized as a key risk factor. Abnormally raised homocysteine has been significantly associated with increased risk of PIH, abruption, intrauterine growth restriction, recurrent pregnancy loss, intrauterine death and prematurity.

Methods: The present case control study was conducted among 180 pregnant women (90 cases and 90 controls) in Kamla Nehru State Hospital for Mother and Child, IGMC Shimla, Himachal Pradesh with an objective of ascertaining the role of homocysteine in pregnancy related hypertensive disorders. Socio-demographic, clinical, biochemical including homocysteine level, laboratory and ultrasonographic parameters of all the participants were documented.

Results: The mean homocysteine level of cases $(18.30 \pm 10.81)$ was significantly higher than the controls (8.70 \pm 2.64$)$. About $62.2 \%$ cases had abnormally raised homocysteine level (>15 $\mu \mathrm{mol} / \mathrm{L})$, while only $1.1 \%$ controls had such level. The odds of a case having abnormally elevated homocysteine level were 146.6 (CI: 19.52-1101) times to that of controls. Eclamptics had the highest homocysteine level followed by preeclamptics and controls.

Conclusions: The present study significantly associates the abnormally elevated homocysteine levels with pregnancy related hypertensive ailments and demands much needed robustly designed studies to further explore the phenomenon. A simple intervention like estimating the much neglected homocysteine levels prior to pregnancy can definitely aid in predicting and preventing perinatal outcomes.
\end{abstract}

Keywords Abnormal homocysteine, Case control study, Eclampsia, Hypertensive disorders of pregnancy, Preeclampsia, Tertiary care institution

\section{INTRODUCTION}

Hypertensive disorders of pregnancy comprising of preeclampsia and eclampsia are a major cause of perinatal adverse outcomes both in terms of adverse maternal and foetal outcomes. ${ }^{1}$ Pre-eclampsia is a multisystem disorder characterized by development of hypertension to the extent of 140/90 mm hg or more with proteinuria after 20 weeks in a previously normotensive and non proteinuric woman. ${ }^{2}$ A pregnant woman is labeled to have eclampsia when pre-eclampsia is complicated with generalized tonic clonic convulsions or coma. ${ }^{3}$ The incidence of preeclampsia is $5-7 \%$ of all pregnancies. ${ }^{4}$ The incidence of eclampsia varies widely and it seen more in primigravida, 
twin pregnancies and in more than half of the cases it occurs between the $36^{\text {th }}$ week and term. ${ }^{3}$ In addition to elevated blood pressure, proteinuria, and convulsions these disorders are further characterized by ominous impaired liver function, increased serum uric acid, decreased platelet count and signs and symptoms such as headache, visual disturbance, epigastric pain and pulmonary odema. ${ }^{5}$ Maternal mortality in eclampsia is high and ranges from $2 \%$ to $30 \%$. Cause of mortality may be cardiac failure, pulmonary edema, aspiration, acute renal failure, cardiopulmonary arrest and adult respiratory distress syndrome. Maternal complications are higher in antepartum eclampsia. ${ }^{6}$

Though endothelial dysfunction and vasospasm have been considered central in pathophysiology of preeclampsia, our understanding of its causal factors and etiology is still minimal. ${ }^{7}$ Theories include abnormal trophoblastic invasion of uterine vessels, discordance of immunologic tolerance between placental and fetal tissues, genetic and dietary factors. ${ }^{8}$ The cause behind cerebral irritation leading to convulsion in pre-eclampsia is not clear. The irritation is postulated to be provoked by anoxia, cerebral edema and cerebral dysrhythmia. The fits are epileptiform and consist of four stages; premonitory stage, tonic, clonic stage and stage of coma. ${ }^{3}$

As evident from vast medical literature, homocysteine, a sulfur containing amino acid has been implicated in the causal pathway of these hypertensive disorders of pregnancy. Normally, in pregnancy serum homocysteine decreases due to hemodilution, increase in estrogen and increased demand for methionine by both mother and fetus. ${ }^{9}$ However, in hyperhomocysteinemia due to any cause such as genetic defects in enzymes involved in homocysteine metabolism and deficiency of folic acid and vitamin $\mathrm{B}_{12}$ which are involved in its biochemical pathways, homocysteine undergoes auto-oxidation to produce reactive oxygen species which inactivate nitric oxide and thrombomodulin which leads to endothelial damage and dysfunction.

It also interferes with fibrinolytic system adding to pathophysiology of preeclampsia and eclmapsia. Increased homocysteine causes increased risk of severe preeclampsia, abruption, intrauterine growth restriction, recurrent pregnancy loss, intrauterine death and prematurity. ${ }^{10}$ Moreover homocysteine lowering therapies in the form of folic acid and vitamin B6 have benefitted patients suffering from pre-eclampsia and eclampsia as seen in previous studies. ${ }^{11}$

With all these considerations in mind and keeping in view lack of any such study in this geographical area and considering the paucity of information on this subject, the present study was conduct at Kamla Nehru State Hospital for Mother and Child, Indira Gandhi Medical College, Shimla to understand the role of homocysteine in hypertensive disorders of pregnancy especially preeclampsia and eclampsia.

\section{METHODS}

The study was conducted among the pregnant women attending antenatal clinic in the Department of Obstetrics and Gynaecology, Kamla Nehru State Hospital for Mother and child IGMC Shimla.

A case control study conducted one year from August 2017 through July 2018.

As it was a time bound study, a total of 90 cases (preeclampsia and eclampsia patients) and 90 age and parity matched controls were included in study.

\section{Inclusion criteria}

- Pregnant women diagnosed with pre-eclampsia and eclampsia at gestational age $>20$ weeks and singleton pregnancy were included in the study.

\section{Exclusion criteria}

- While women with diabetes mellitus, essential hypertension, liver disease, severe anaemia, multiple pregnancies and with treatment on anti-folate drugs were excluded.

A study proforma was designed to collect and record socio-demographic parameters, antenatal history, previous medical and reproductive history, clinical signs and symptoms, laboratory investigations, ultrasonic findings, plan and mode of delivery and maternal/foetal outcomes were recorded on the proforma.

All the pre-eclampsia and eclampsia patients admitted in labor were taken as cases. For every case, a consecutive age and parity matched control was included in the study. On admission detailed obstetric, menstrual, medical, treatment and dietary history were noted. Warning signs and symptoms such as vomiting, blurring of vision, headache, pain-epigastrium were inquired from the patients. General physical examination, systemic and obstetrics examination was done as per standard protocol. Routine and special investigations (renal function tests, liver function tests) were also done. Maternal homocystenine level was measured by chemoluminescent enzyme method in all cases and controls using Abbott immunoassay analyser 1000/r.

Subjects with severe pre-eclampsia and eclampsia were managed with antihypertensive and prophylactic magnesium sulphate using standard management protocol. Maternal and foetal outcomes were documented.

\section{Statistical analysis}

Data were entered into Microsoft Excel spreadsheet, cleaned and transferred to Epi Info version 7.2.2.6 software for analysis. Continuous variables were 
presented as mean scores \pm standard deviations while discrete variables as percentages and proportions of each. Pearson's Chi-squared or Fisher Exact test and Chisquared for trend test was used to test the statistical significance of dichotomous and ordered categorical data respectively. Mean homocysteine level of groups was compared using Independent t-test or ANOVA test and further Tukey Post hoc test was applied wherever necessary. Odds ratio with $95 \%$ Confidence intervals were calculated to find out the strength of association between exposure and outcome variable. Two tailed $\mathrm{P}$ value $<0.05$ was considered as statistically significant for all analysis.

\section{Ethical considerations}

Prior permission was taken from Institute Ethical Committee. Personal identifiers were omitted in order to maintain confidentiality and anonymity. Potential harms and benefits were explained to the patient and guardian before taking consent. Patient was free to leave the study at any point of time and this didn't affect her clinical care. No financial expenditure was incurred by the patient for the sake of study.

\section{RESULTS}

A total of 180 antenatal women at period of gestation more than 20 weeks were enrolled. The study group included 90 women beyond 20 weeks of gestation with hypertension fulfilling inclusion criteria. Consecutive age and parity matched 90 normotensive women were taken as controls. Among 90 cases, 69 were pre-eclamptics while 21 were labelled as eclampsia. Maternal serum homocysteine level was measured in all enrolled participants. Depending upon the homocysteine levels, the subjects were further divided into two groups, with normal homocysteine levels $(<15 \mu \mathrm{mol} / \mathrm{L})$ and with hyperhomocystenemia ( $\geq 15 \mu \mathrm{mol} / \mathrm{L})$. There was only one subject in control group who had hyperhomocystenemia.

Table 1: Socio-demographic and baseline characteristics of study participants.

\begin{tabular}{|c|c|c|c|c|c|}
\hline Attribute & Sub-category & Cases $\mathbf{n}=90(\%)$ & Controls $\mathrm{n}=90(\%)$ & $P$ value & Odds Ratio \\
\hline \multirow{6}{*}{ Age } & $<20$ years $(\mathrm{n}=11)$ & $9(10)$ & $2(2.2)$ & \multirow{5}{*}{$0.219^{*}$} & 1 \\
\hline & $20-25$ years $(n=72)$ & $37(41.1)$ & $35(38.9)$ & & 0.24 \\
\hline & $25-30$ years $(n=57)$ & $26(28.9)$ & $35(38.9)$ & & 0.17 \\
\hline & $31-35$ years $(n=26)$ & $13(14.4)$ & $13(14.4)$ & & 0.22 \\
\hline & $>35$ years $(n=10)$ & $5(5.6)$ & $5(5.6)$ & & 0.22 \\
\hline & Mean age & $23.5 \pm 2.3$ & $25.5 \pm 3.5$ & - & - \\
\hline \multirow{2}{*}{ Parity } & Primigravida $(n=136)$ & $70(77.8)$ & $66(73.3)$ & \multirow{2}{*}{$0.603^{* *}$} & \multirow{2}{*}{$1.27(0.64-2.52)$} \\
\hline & Multigravida (n=44) & $20(22.2)$ & $24(26.7)$ & & \\
\hline \multirow{2}{*}{$\begin{array}{l}\text { Booking } \\
\text { status }\end{array}$} & Unbooked (n=9) & $3(3.3)$ & $6(6.7)$ & \multirow{2}{*}{$0.497^{* *}$} & \multirow{2}{*}{$0.48(0.12-1.99)$} \\
\hline & Booked $(n=171)$ & $87(96.7)$ & $84(93.3)$ & & \\
\hline \multirow{2}{*}{ Residence } & Rural (n=117) & $54(60)$ & $63(70)$ & \multirow{2}{*}{$0.211^{* *}$} & \multirow{2}{*}{$0.64(0.34-1.19)$} \\
\hline & Urban $(n=63)$ & $36(40)$ & $27(39)$ & & \\
\hline \multirow{3}{*}{$\begin{array}{l}\text { Socio- } \\
\text { economic } \\
\text { status }\end{array}$} & Upper, upper middle $(n=9)$ & $7(7.8)$ & $2(2.2)$ & \multirow{3}{*}{$0.088^{*}$} & 1 \\
\hline & Lower middle $(n=109)$ & $51(56.7)$ & $58(64.4)$ & & 0.251 \\
\hline & lower $(n=62)$ & $32(35.6)$ & $30(33.3)$ & & 0.305 \\
\hline
\end{tabular}

*Chi-Squared test for proportions; **Chi-Squared test for trends.

Table 2: Serum homocysteine levels among cases and controls.

\begin{tabular}{|c|c|c|c|c|c|}
\hline Homocysteine level & $\begin{array}{l}\text { Homocysteine level } \\
\text { ( } \mu \mathrm{mol} / \mathrm{L})\end{array}$ & Cases $n=90(\%)$ & Control $\mathrm{n}=90(\%)$ & P value & Odds ratio $(95 \% \mathrm{CI})$ \\
\hline \multirow{2}{*}{ Normal } & $<3$ & 0 & $5(5.5)$ & \multirow{4}{*}{$<0.001^{*}$} & \multirow{4}{*}{$\begin{array}{l}146.6 \\
(19.52-1101)\end{array}$} \\
\hline & $3-14.9$ & $34(37.7)$ & $84(94.4)$ & & \\
\hline \multirow{2}{*}{ Elevated } & $15-26.5$ & $37(41.1)$ & $1(1.1)$ & & \\
\hline & $27-50$ & $19(21.1)$ & 0 & & \\
\hline \multicolumn{2}{|c|}{ Mean homocysteine level } & $18.30 \pm 10.81$ & $8.70 \pm 2.64$ & $<0.001^{* *}$ & - \\
\hline
\end{tabular}

*Chi- squared test for proportions;**Independent t-test

Table 1 highlights the socio-demographic and baseline characteristics profile of the both cases and controls enrolled in the study. The two groups had no statistically significant difference for the attributes like age, parity, residence, booking status and socio-economic status. This ensured the comparability and matching of the two 
groups included for the study purpose. In cases there were more primigravidae patients, because hypertension is more common in primigravidae as evident by available medical literature. Among cases, $37.7 \%$ subjects had homocysteine level between 3-14.9 $\mu \mathrm{mol} / \mathrm{L}, 41.1 \%$ had homocysteine level between $15-26.5 \mu \mathrm{mol} / \mathrm{L}$ and $21.1 \%$ had homocysteine levels between 27-50 $\mu \mathrm{mol} / \mathrm{L}$. In controls, 5.5\% had homocysteine level below $3 \mu \mathrm{mol} / \mathrm{L}$, 94.4\% had homocysteine level between 3-14.9 $\mu \mathrm{mol} / \mathrm{L}$ and $1.1 \%$ had level between $15-26.5 \mu \mathrm{mol} / \mathrm{L}$.

Table 3: Serum homocysteine levels among eclampsia and preeclampsia.

\begin{tabular}{|lllll|}
\hline Homocysteine $(\mu \mathrm{mol} / \mathrm{L})$ & Eclampsia $\mathrm{n=21}(\%)$ & Pre-eclampsia $\mathrm{n=69}(\%)$ & P Value & Odds ratio $(95 \%$ CI) \\
\hline Elevated $(\geq 15)(\mathrm{n}=56)$ & $18(85.7)$ & $38(55.1)$ & $0.023^{*}$ & 4.89 \\
\hline Normal $(<15)(\mathrm{n}=34)$ & $3(14.3)$ & $31(44.9)$ & $<0.001^{* *}$ & - \\
\hline Mean homocysteine level & $24.44 \pm 13.29$ & $16.43 \pm 9.27$ & &
\end{tabular}

Table 4: Comparing homocysteine in preeclampsia, eclampsia and controls.

\begin{tabular}{|llll|}
\hline Testing group & Against group & Mean difference $(95 \% \mathrm{CI})$ & P value \\
\hline \multirow{2}{*}{ Controls } & Pre-eclampsia & $-7.73(-10.57$ to -4.88$)$ & $<0.001^{*}$ \\
\cline { 2 - 4 } & Eclampsia & $-15.73(-20.04$ to -11.43$)$ & $<0.001^{*}$ \\
\hline Eclampsia & Pre-eclampsia & $8.00(3.57$ to 12.43$)$ & $<0.001^{*}$ \\
\hline
\end{tabular}

It was further observed that $62.2 \%$ cases had homocysteinemia $(\geq 15 \mu \mathrm{mol} / \mathrm{L})$, while only $1.1 \%$ controls had raised levels. The odds of a case to have homocysteinemia were 146.6 (CI: 19.52-1101) times to that of controls. This difference was found to be statistically significant. The mean serum homocysteine level in cases $(18.30 \pm 10.81)$ was statistically significantly higher than controls $(8.70 \pm 2.64)$.

On comparing the pre-eclampsia and eclampsia patients, 85.7\% eclamptics cases had homocysteinemia while $55.1 \%$ pre-eclampsia cases had raised homocysteine levels. The odds of eclampsia cases having raised homocysteine levels were 4.89 (CI: 1.32-18.16); with difference being statistically significant $(\mathrm{P}=0.023)$ (Table 3).

In the present study, homocysteine ranged between 3.5 $15 \mu \mathrm{mol} / \mathrm{L}$ in controls with mean homocysteine level of $8.70 \pm 2.64 \mu \mathrm{mol} / \mathrm{L}$. In pre-eclampsia patients, homocysteine ranged between $6-50 \mu \mathrm{mol} / \mathrm{L}$ with mean level of $16.43 \pm 9.27 \mu \mathrm{mol} / \mathrm{L}$ and for eclampsia group the homocysteine ranged between $8-50 \mu \mathrm{mol} / \mathrm{L}$ and the mean was found to be $24.44 \pm 13.29 \mu \mathrm{mol} / \mathrm{L}$. This difference was found to be statistically significant $(\mathrm{P}<0.001)$ (Table 2 and 3$)$.

On further applying Tukey Post hoc test, the mean difference between the pre-eclampsia group and control group was 7.73 (CI: 4.88-10.57), between eclampsia and controls was 15.73 (CI: 11.43-20.04) and between eclampsia and pre-eclampsia groups was found to be 8.00 (CI: 3.57-12.43). All these differences were found to be statistically significant (Table 4).

\section{DISCUSSION}

The mean age of women in case and control groups was $23.5 \pm 2.3$ and $25.5 \pm 3.5$ years respectively. This was comparable to the studies conducted by Sangeeta et al, Miglani et al and Jain et al. ${ }^{12-14}$ In the present study about $77.7 \%$ participants were primigravidae among cases, which was similar to the findings observed by Sangeeta $\mathrm{N}$ et al, and Makedos $\mathrm{G}$ et al. ${ }^{12,15}$ Higher number of primigravidae was observed in the study group as pregnancy induced hypertension tends to be more in primigravidae.

The present study observed that the mean homocysteine levels in normotensive group, preeclampsia and eclampsia group was $8.70 \pm 2.64 \mu \mathrm{mol} / \mathrm{L}, 16.43 \pm 9.27$ $\mu \mathrm{mol} / \mathrm{L}$ and $24.44 \pm 13.29 \mu \mathrm{mol} / \mathrm{L}$ respectively. The mean homocysteine level in normotensives, pre-eclampsia and eclampsia patients observed in present study was comparable to the observations made in the studies conducted by Yelikar et al, Ignec et al, Sangeeta et al, Meera V et al, Shilpa AV et al, Patil $\mathrm{N}$ et al, and Nidumuru et al. ${ }^{4,9,12,16-19}$

Moreover, as we moved from lower severity to higher severity in the spectrum of hypertensive disorders of pregnancy the homocysteine level kept increasing. This finding further commensurates pregnancy induced hypertension with the homycysteinemia and supports our hypothesis that serum homocysteine is raised in preeclampsia and there is an association between preeclampsia and hyperhomocysteinemia.

It was further observed that $62.2 \%$ cases had abnormally elevated homocysteine levels $(\geq 15 \mu \mathrm{mol} / \mathrm{L})$, while only 
$1.1 \%$ controls had raised levels. The odds of a case being homocysteinemic were significantly higher than controls (OR: 146.6, CI: 19.52-1101). Moreover, the cases had significantly higher mean serum homocysteine level than controls (Cases: 18.30 \pm 10.81 versus Controls: $8.70 \pm 2.64)$.

About $85.7 \%$ of eclampsia patients had homocysteinemia while $55.1 \%$ pre-eclampsia cases had raised homocysteine levels. Eclampsia cases were significantly more likely to have abnormally raised homocysteine levels than pre-eclamptics (OR: 4.89, CI: 1.32-18.16).

These findings corroborate the point that hyperhomocysteinemia due to its direct vascular endothelial injury and prothrombotic effect on the coagulatory system has a potential role in the pathogenesis of preeclampsia. Metabolism in the kidney is the major route by which homocysteine is cleared from plasma and this route of elimination may be affected by preeclamptic changes in the kidney. ${ }^{20}$

The present study was a time bound study and the sample size was chosen arbitrarily. Moreover, the study participants were enrolled using convenience sampling method. This might have affected the generalizability and external validity of the study.

\section{CONCLUSION}

The present study underpins serum homocysteine level in the pathogenesis and causal pathway of hypertensive disorder of pregnancy. Moreover, it also generates the region specific baseline data on this important but negligibly studied aspect of pregnancy related hypertensive ailments. Its further highlights that degree of severity of pregnancy induced hypertension is proportionate to the levels of homocysteine.

Routine estimation of homocysteine levels prior to pregnancy may help to correctly predict and prevent further development of preeclampsia and eclampsia, if timely countermeasures are undertaken. In the current era of women empowerment and free of cost maternal care, it is strongly recommended that the women with a history adverse pregnancy outcome undergo the screening for hyperhomocystenemia.

It is further recommended that more robust study designs should be employed to understand this phenomenon. A well-designed cohort study with sound methodology and adequate sample size can definitely aid in ascertaining the temporality and causal association between homomocysteine and hypertensive disorders of pregnancy. In addition, interventional trials are required to show whether dietary replacement or supplementation with factors implicated in metabolic pathway of homocysteine will decrease the incidence of hyperhomocystenemia which in turn will decrease the incidence of adverse pregnancy outcome associated with it.

Funding: No funding sources

Conflict of interest: None declared

Ethical approval: The study was approved by the Institutional Ethics Committee

\section{REFERENCES}

1. Mujawar SA, Patil VW, Daver RG. Study of serum homocysteine, folic acid and vitamin B12 in patients with preeclampsia. Ind $\mathrm{J}$ Clin Biochem. 2011;26(3):257-60.

2. Dekker G, Sibai B. Etiology and pathogenesis of preeclampsia: Current concepts. Am J Obstet Gynecol. 1998;179:1359-75.

3. Dutta DC. Textbook of Obstetrics. 9th Ed. Jaypee Brothers Medical Publishers; 2015: 217-220.

4. Yelikar K, Deshpand S, Kulkarni M. Association of maternal homocysteine level with severity of preeclampsia. Int J Reprod Contracept Obstet Gynecol. 2016;5(8):2713-7.

5. Gifford R, August P, Chesley L. National high blood pressure education program working group report on high blood pressure in pregnancy. Am $\mathrm{J}$ Obstet Gynecol. 1990;163:1689-712.

6. Cunningham FG, Leveno KJ, Bloom SL, Hauth JC, Rouse DJ, Sponge CY. In: Williams Obstetrics. 25th ed. New York: McGraw Hill Company. 2018:15759.

7. Witlin AG, Sibai BM. Magnesium sulfate therapy in preeclampsia and eclampsia. Obstet Gynecol. 1998;92:883-9.

8. Refsum H, Ueland PM, Nygard O, Vollset SE. Homocysteine and cardiovascular disease. Ann Rev Med. 1998;49:31-62.

9. Ingec M, Borecki B, Kadanli S. Elevated Plasma Homocysteine Concentrations in Severe Preeclampsia and Eclampsia. Tohoku J Exp Med. 2005;206(3):225-31.

10. Hoque MM, Bulbul T, Mahal M, Islam NA, Ferdausi M. Serum homocysteine in preeclampsia and eclampsia. Bangladesh Med Res Counc Bull. 2008;34:16-20

11. Arun M, Gopinath M, Nirmala C. Prevalence of hyperhomocysteinemia among preeclampsia patients. J Med Sci Clin Res. 2017;5(4):21063-9.

12. Sangeeta N, Shaini L, Gomi B, Devi S, Chhuangi V, Mandal KK, et al. Serum Uric Acid and Homocysteine as Predictors of Pre-eclampsia. J Diabetes Metab. 2013;4:259.

13. Miglani S, Nautiyal R, Prakash A. Hyperhomocysteinemia in pre-eclampsia: Is routine screening rational?. Int J Reprod Contracept Obstet Gynecol. 2017;6(4):1271-4.

14. Jain N, Singh A, Bhattacharjee J. Serum homocysteine and folate levels as a predictor of materno-fetal outcome in preeclamptic women. Int $\mathbf{J}$ 
Reprod Contracept Obstet Gynecol. 2018;7(12):4939-44.

15. Makedos G, Papanicolaou A, Hitoglou A, Kalogiannidis I, Makedos A, Vrazioti V, et al. Homocysteine, folic acid and B12 serum levels in pregnancy complicated with preeclampsia. Arch Gynecol Obstet. 2007;275:121-4.

16. Meera V, Goutham ESA. A study of homocysteine and uric acid levels in pregnancy induced hypertension. National J Basic Med Sci. 2017;7(4):215-9.

17. Shilpa AV, Zubaida PA, Rajalekshmi G. Changes in homocysteine levels during normal pregnancy and preeclampsia and its relation with oxidative stress. Int J Res Med Sci. 2017;5(1):330-4.

18. Patil N, Shirdi S, Abhig V. A case control study to compare the levels of homocysteine in normal and complicated pregnancies. Indian J Obst Gynecol Res. 2018;5(1):41-3.
19. Nidumuru S, Kishan RH. A study of serum homocysteine levels in pre-eclampsia and eclampsia in a tertiary care hospital. Sch J App Med Sci. 2018;6(9):3357-60.

20. Mignini L, Latthe P, Villar J, Kilby M, Carroli G, Khan K. Mapping the theories of preeclampsia: The role of homocysteine. Obstet Gynecol. 2005;105:411-25.

Cite this article as: Pathania K, Verma SK,

Chamotra S, Chaudhary A. Can serum homocysteine predict hypertensive disorders of pregnancy?: an evidence from a case control study in a North Indian tertiary health care institution. Int J Reprod Contracept Obstet Gynecol 2019;8:3117-22. 